\title{
RETRACTED ARTICLE Recent progress in AFM studies of biodegradable poly(lactic acid) materials
}

\author{
ZENG Chao ${ }^{1}$, ZHANG NaiWen ${ }^{2} \&$ REN Jie ${ }^{1,3}$ \\ ${ }^{1}$ Institute of Nano- and Bio-polymeric Materials, School of Materials Science and Engineering, Tongji University, Shanghai 200092, China; \\ ${ }^{2}$ Shanghai Tong-jie-liang Biomaterials Co., Ltd, Shanghai 200438, China; \\ ${ }^{3}$ Key Laboratory of Advanced Civil Engineering Materials, Ministry of Education, Tongji University, Shanghai 200092, China
}

The authors have voluntarily retracted article [Zeng C, Zhang N W, Ren J. Recent progress in AFM studies of biodegradable poly(lactic acid) materials. Chin Sci Bull, doi: 10.1007/s11434-012-5052-z] because of portions of the article are similar to a previous publication [Yuryev Y, Wood-Adams P, Brisson J, et al. Crystallization of polylactide films: An atomic force microscopy study of the effects of temperature and blending. Polymer, 2008, 49: 2306-2320]. While there was no intention to use pre-existing work without appropriate attribution, the authors apologize to all affected parties for the inconvenience.

Open Access This article is distributed under the terms of the Creative Commons Attribution License which permits any use, distribution, and reproduction in any medium, provided the original author(s) and source are credited. 